\title{
User Roles in Virtual Community of Crowdsourcing for Innovation: A Case Study of Xiaomi MIUI in China
}

\author{
Qingliang MENG, Yi HANG, Xiaojun CHEN
}

\begin{abstract}
Crowdsourcing innovation, as a new innovation pattern, helps companies reduce the risks and costs of innovation, which has received widespread attention and practical application. What is critical for improving crowdsourcing innovation performance is to understand the heterogeneity of participating users deeply, guide and motivate users to participate actively. Based on the typical characteristics of crowdsourcing innovation communities, this paper proposes a model integrating social network analysis (SNA) \& K-means clustering algorithm to identify participants' roles and conducting empirical research with Xiaomi MIUI community. The result indicates that users can be divided into nine categories: active user, positive user, negative user, bystander, creative contributor, faithful supporter, tourist, and new participant. In order to provide decision support for enterprises to govern crowdsourcing innovation virtual community effectively and improve innovation performance, this paper analyses the behavioural characteristics of each user role from two dimensions: interaction behaviour and contribution behaviour.
\end{abstract}

Keywords: crowdsourcing innovation; identification; user roles; virtual community

\section{INTRODUCTION}

Crowdsourcing innovation refers to the business pattern in which enterprises carry out traditional innovation tasks that used to be performed by internal employees to external users (the public) in a free and voluntary manner [1]. This model has been proved to be effective for acquiring external network knowledge resources [2]. For example, $P \& G$ draws support from InnoCentive, which has increased the proportion of external-innovation from $15 \%$ to $50 \%$; consequently, its R\&D capability has increased by $60 \%$. The IdeaStorm crowdsourcing community created by Dell has collected more than 28,577 ideas to date, and more than 550 ideas have been implemented. Starbucks relies on MyStarbucksIdea crowdsourcing innovation community to continuously collect external ideas, promote brand awareness, and the product\&service innovation concept. Xiaomi MIUI community, with more than 47 million registered users, plays a critical role in carrying out seamless open innovation activities. Due to the "full participation of the public", Xiaomi grows rapidly. It can be seen that the innovation pattern of the enterprise has been deeply affected by crowdsourcing innovation, and abundant different innovation patterns have been proposed.

Since Howe (2006) first proposed the concept of crowdsourcing as a pattern for achieving innovation task [1], crowdsourcing innovation has attracted intense public attention. Jeppesen et al. [3] believe that crowdsourcing related tasks used to be completed within the traditional enterprise, are accomplished by non-specific external network groups through open tendering at present. After the individual submits the plan separately, the contractor who was selected as the first place will win the reward. Brabham [4] describes crowdsourcing as a series of processes for "enterprise publish issues online - the public (professional or non-professional) submit solutions winner gets paid", and the company owns the intellectual property. It is an online problem-solving model or a production model. Geiger [5] suggests that crowdsourcing is an information system pattern that leverages the potential of internal and external users to deliver innovative products or services. Mozan et al. [6] also propose that crowdsourcing is a collaborative model that is humancentered, network-driven, and used to solve personal, organizational or social problems, which is from the perspective of information systems.

However, as a new business pattern, crowdsourcing innovation is still in the groping stage, and the research achievements are fragmented [7]. Although the practice of crowdsourcing innovation has achieved certain results, it still has imperfections, such as the needs to improve the quality of innovation [8], the transient user participating [9, $10]$, etc. For Chinese enterprises, in recent years, they also have established some crowdsourcing innovative virtual communities (e.g., Haier HOPE, Midea Meichuang platform, etc.) and intermediary crowdsourcing platforms (e.g.,zhubajie, Mission China, etc.), but their applications remain in the primary scope of information processing and simple innovation tasks. The lack of mainstream enterprises to participate in China, is in contrast to leading companies that spare no pains to create crowdsourcing innovation models. One of the main reasons is that enterprises lack a systematic understanding of crowdsourcing innovation pattern, confidence in application, and theoretical guidance.

As a new innovative mode, crowdsourcing innovative community effectively obtains product or service ideas and achieves innovation through constructing a virtual environment, gathering the external public, setting up appropriate guidance and rewarding mechanisms. Appreciating the heterogeneity of participating users is the basis for governing the virtual community effectively [11]. Only by deeply understanding the users' participation behavior and participation characteristics in the virtual community and adopting targeted guidance and incentive strategies can the innovation plan be effectively appreciated [12]. The current research focuses on the classification of user roles in general social virtual communities, the structure of relational networks, etc. [13]. And a few are focused on innovative virtual communities with typical features of strong innovation goals and clear reward mechanisms, etc. [14, 15]. There are also some studies that explore the Leading Users identification 
problem of crowdsourcing innovative virtual communities [16].

In the context of the internet developed as global mainstream communication media [17], virtual communities provide a new way to achieve social convenience, user-generated content, and innovative task resolution [18], while the persistence and effectiveness of virtual communities depend on their identification, guidance, and management of heterogeneous users $[11,15,19]$. Therefore, research on user roles in virtual communities has attracted extensive attention. According to the different purposes of virtual community construction, it can be divided into consume-social virtual communities and crowdsourcing innovative virtual communities. For consume-social virtual communities, relevant research focuses on the identification of specific roles (Influencer, Opinion Leader and Experts) [20], mostly from the status of user network, participation behavior and the contribution of knowledge sharing. In contrast, the crowdsourcing innovative virtual community is highly innovative, and the research is focus on the identification of the Leader Users and the Innovative Users $[19,21]$. Both of them possess the following characteristics: strong innovative motivation and high returns expectation from the solution; ahead of the general user needs and the potential of becoming opinion leaders; the wealth of relevant knowledge and strong innovation capabilities. However, practice proves that not all Leading Users' ideas can be adopted. The adoped creation is also related to the companys' absorptive capacity and strategic layout [21]. Tab. 1 summarizes the relevant research literature about user roles of crowdsourcing innovative virtual communities.

Table 1 The correlation researches of user roles [11, 14, 15, 22, 23, 24]

\begin{tabular}{|c|c|c|c|c|}
\hline Authors & Indicators & User roles & Empirical objects & Methods \\
\hline Liu et al. [22] & $\begin{array}{l}\text { User engagement behavior } \\
\text { (contribution value, } \\
\text { participation level) }\end{array}$ & $\begin{array}{l}\text { Potential users, Core Users, } \\
\text { General Users, and Powerful Users }\end{array}$ & $\begin{array}{l}\text { Xiaomi MIUI "New } \\
\text { Features Discussion" } \\
\text { section }\end{array}$ & Regression analysis \\
\hline Qi et al. [23] & $\begin{array}{l}\text { Idea submitted, Scores, } \\
\text { comment submitted }\end{array}$ & $\begin{array}{l}\text { Core Users, Active Social Users, } \\
\text { Glamorous Social Users, Active } \\
\text { And Innovative Users, Effective } \\
\text { Innovative Users, Passive Users }\end{array}$ & My Starbucks Idea & Cluster analysis \\
\hline Toral et al. [24] & Out-degree, betweenness & $\begin{array}{l}\text { Edge users, general users, core } \\
\text { users }\end{array}$ & $\begin{array}{l}\text { Linux open source software } \\
\text { community }\end{array}$ & Network analysis \\
\hline Füller et al. [11] & $\begin{array}{l}\text { Out-degree, In-degree, the } \\
\text { number of contributions }\end{array}$ & $\begin{array}{l}\text { Socializer, idea generator, master, } \\
\text { efficient contributor, passive ideas } \\
\text { generator, passive commentator. }\end{array}$ & Swarovski DIY Community & $\begin{array}{l}\text { Social network analysis } \\
\text { and Cluster analysis }\end{array}$ \\
\hline Guo et al. [14] & $\begin{array}{l}\text { The number, popularity, and } \\
\text { impact of user creation in the } \\
\text { community }\end{array}$ & $\begin{array}{l}\text { Project leader, Active designer, } \\
\text { Generalist, Communicator, Passive } \\
\text { designer, Observer }\end{array}$ & $\begin{array}{l}\text { Self-built community of a } \\
\text { local car manufacturer }\end{array}$ & $\begin{array}{l}\text { Social network analysis } \\
\text { and Cluster analysis }\end{array}$ \\
\hline Fuger et al. [15] & $\begin{array}{l}\text { Out-degree, In-degree, the } \\
\text { number of contribution }\end{array}$ & $\begin{array}{l}\text { Collaborator, Contributor, } \\
\text { Allrounder, Passive User }\end{array}$ & OpenIDEO & $\begin{array}{l}\text { Cluster and social } \\
\text { network analysis }\end{array}$ \\
\hline
\end{tabular}

Therefore, it is a necessary condition for further refining the user role of crowdsourcing innovative virtual communities. SNA allows a precise visualization of social network and the interaction in crowds and K-means clustering algorithm can minimize the variation within and maximize the variation between groups. Based on the typical characteristics of crowdsourcing innovation community, this paper proposes a user role recognition model integrating social network and K-means clustering algorithm, and conducts empirical research with Xiaomi MIUI community as an example to illustrate an effective decision support for enterprises in launching crowdsourcing innovation.

\section{METHODS}

In order to make research more universal and understand the users' heterogeneity and contribution behavior deeply, this paper integrates the typical characteristics of crowdsourcing innovation (e.g., strong innovation purpose, clear reward mechanism and high knowledge sharing demand) to establish a process to identify users' roles in crowdsourcing innovative virtual communities. Figure 1 shows the user roles recognition process of the crowdsourcing virtual community, mainly including research settings and data collections, identification system construction, user roles identification by social network analysis and K-means clustering algorithm and analysis of users'participation behavior characteristics.

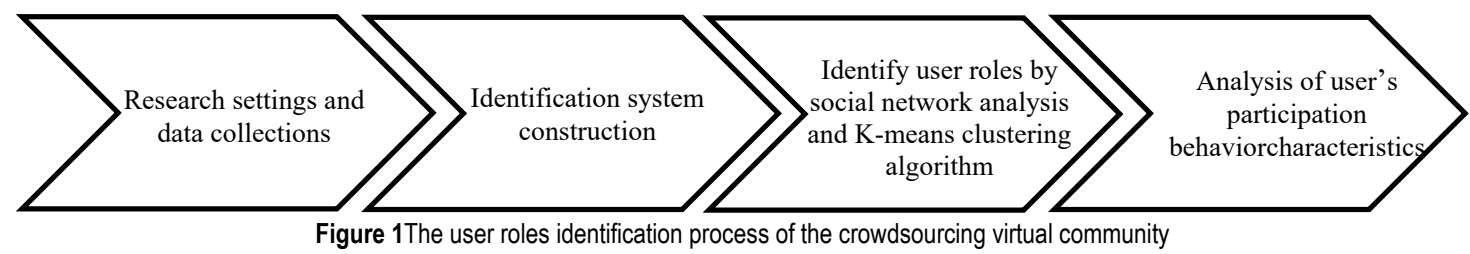

\subsection{Research Settings and Data Collections}

The purpose of the research settings is to determine the scope of participants. Considering that the crowdsourcing community has a wide range of participate users, free and voluntary participation and relative dispersed organizations, participating users will be involved in many areas of the community (or sections), such as product services, social, creative acquisition, etc. Some communities have strong social characteristics, some communities have strong consumer characteristics, and the research object of this paper is defined as a crowdsourcing community with innovative features.

The MIUI community is a self-owned platform of Xiaomi Company, which is built to facilitate communication, consultation, assist, complaints and 
suggestions for its users. It is one of the best innovative virtual communities in China. The MIUI community is divided into 12 sections, with a total of 22.52 million registered users. The platform has posted a total of 10.35 million posts for users to communicate and promote product innovation. The "developer communication" section is the main section of communication between community users and development team, with regard to exchanging ideas and promoting product development. Users who have obtained the honorary title of "official version group", "honor development group" and "internal test fan group" can get material or virtual rewards from Xiaomi by completing the officially released task. Therefore, this article selects the "developer communication" section as the research object of user role recognition.
Using the web crawler collector (Octopus version 7.5.4), user-related data is obtained from October 2014 to November 2018. 3,304 ideas/suggestions submitted by 1,134 users and 30,720 comments submitted by 1,025 users were obtained. The paper collects a total of 20054 users' information (including 105 users submitting ideas/suggestions and submitting comments). Since each participating user has his or her specific ID, the relationship between each user and other users can be determined.

\subsection{Construction of Identification System}

As mentioned before, the relevant literature rarely identifies user roles from the two dimensions of interaction behavior and contribution behavior. Thus, the identification system is shown in Tab. 2 .

Table 2 User roles identification system for crowdsourcing innovative virtual communities

\begin{tabular}{|l|c|c|c|}
\hline \multicolumn{1}{|c|}{ Target } & Main dimensions & Measurement standards & \multicolumn{2}{|c|}{ Remarks } \\
\hline \multirow{3}{*}{$\begin{array}{l}\text { Identification of user roles in } \\
\text { crowdsourced innovative virtual } \\
\text { communities }\end{array}$} & Interaction behavior & Out-degree & The number of published creatives and replies posted by users \\
\cline { 2 - 4 } & & In-degree & $\begin{array}{l}\text { The number of comments the user received, the number of } \\
\text { agree points, and the number of votes received }\end{array}$ \\
\cline { 2 - 4 } & Contribution behavior & Contribution point & $\begin{array}{l}\text { The number of officially recognized creative quantities and the } \\
\text { number of purchasing or evaluating company products }\end{array}$ \\
\cline { 3 - 4 } & & $\begin{array}{l}\text { The number of ideas unrecognized by MIUI and the number of } \\
\text { creative suggestions for other users, etc. }\end{array}$ \\
\cline { 3 - 4 }
\end{tabular}

Interaction behavior of participating users: Combined with social network analysis methods, the user's interaction behavior is measured mainly from the aspects of out-degree and in-degree. In the community, participants can come up with ideas, comment on others' ideas, and accept comments from other users about their ideas. The in-degree (the number of comments received, the number of likes received, and the number of votes received) represents the interaction behavior of all other users on one user; the out-degree (the number of published creatives and the number of replies posted by users) represents the user's interaction with other users. Interaction behavior, using the degree centrality, can determine the popularity or activity of the user.

Contribution behavior of participating users: The innovative purpose is the main characteristic of the crowdsourcing innovation. It is necessary to take the concrete contribution of users' innovation performance to consideration. Contribution values can be used to measure users' direct contribution behavior to innovation, while user credits measure users' indirect contribution behavior because the user's contribution value represents the number of ideas recognized officially and the number of the products they have purchased and evaluated. The user credits depend on the number of ideas unrecognized by MIUI and the number of creative suggestions for other users.

\subsection{Identify User Roles by Social Network Analysis and K- means Clustering Algorithm}

Based on the user role recognition system of crowdsourcing innovative virtual community in Tab. 2, this paper puts forward the identification method by integrating SNA and K-means clustering algorithm. Social network analysis (SNA) is a multi-disciplinary measurement method that integrates applied mathematics, graph theory, and computer. It can be used to measure, evaluate and visualize the individual relationship model in the relational network, and has unique advantages in understanding the network structure relationship. K-means clustering algorithm is a simple, practical and typical clustering method based on the distance between samples. By integrating the SNA and K-means clustering algorithm, the relationship behavior characteristics and the contribution behavior characteristics of user participation in crowdsourcing innovation community are taken into account, which enables administrators to understand user behavior comprehensively [25].

(1) Social network analysis (SNA): SNA is a set of norms for qualitative research and quantitative discussion of social relationship structures and their attributes. It has the advantage to analyze networks with multiple nodes and multiple subjects. The social network analysis method consists of nodes and connections, where nodes represent the actors in the event and connections represent the relationship between them. This is a method of studying the dynamic relationship between multiple entities, which forms a relationship network diagram. SNA mainly analyzes the characteristics of the relationship network structure from the out-degree, in-degree, clique, and centrality. It can also analyze and explore the whole network from the perspectives of overall network structure visualization, network density, and small world effect. Considering the crowdsourcing innovation community has the characteristics of multi-agent participation, multi-layer interaction, dynamic change of relationship, and so on it is more appropriate to use SNA to study the user identification of the crowdsourcing innovation virtual community.

(2) K-means clustering algorithm: Among various cluster analysis methods, K-means clustering algorithm is widely used due to high efficiency and no need to predict in advance to determine the input-output relationship 
[26,27]. The basic principle is to specify the number of clusters $K$, cluster the sample sets, and divide the $N$ objects into $K$ clusters. Then, there is a higher similarity within the cluster, but a lower similarity between the clusters [28]. The basic steps are as follows: specify the number of clusters $(K)$; Define the $K$ initial cluster center points of the sample; calculate distance from the $K$ initial cluster $K$ centers for each sample point and classify the point into the cluster with the smallest distance; classify the cases to the $K$ classes according to the nearest distance principle temporary; then calculate the mean of each variable according to the samples that make up each class, and the $N$ mean values of each class form $K$ points in the $\mathrm{N}$ dimensional space again, which is the class center of the second iteration; iteratively follows the method until the specified number of iterations or the criterion of the iteration reach request, the iteration is ended, and the clustering process ends. The key to K-means clustering algorithm is to select the initial cluster centers. Different initial clusters often lead to different classification results. The main disadvantage is that the number $K$ of clusters used to be given in advance randomly, which is likely to result in low clustering accuracy and unstable clustering results. There are many methods for determining $K$ value, such as empirical method, density method, one-by-one classification method, mountain climbing method, recursive method and other algorithms. Considering that crowdsourcing innovation belongs to the new innovation mode, there are less researches on user role recognition in this mode. Therefore, sum of the squared errors $(S S E)$ is used to evaluate the K-means clustering effects, and then the elbow method is used to determine the $K$ value.

\subsection{Analysis of User's Participation Behaviour Characteristics}

The ultimate goal of user role recognition is to understand the different effects of different users in crowdsourcing innovation and identify critical users who contribute perfectly to innovation performance. By analyzing the behavioral characteristics of these users, scientific and effective guidance and incentive strategies are adopted to ensure healthy development of the innovative virtual community. Therefore, the behavior analysis process based on the recognition result is very necessary. It is indispensable to analyze the behavior characteristics of the crowdsourcing innovation virtual community from multiple dimensions, including its related humanistic statistical characteristics data, interaction behavior and contribution data, etc. Through multidimensional comparison, the guidance and motivation strategies of users in different roles are given in combination with the practice of specific enterprises.

\section{RESULTS}

Fig. 2 visualizes the sociogram of the social network based on the interaction behavior of users throughout the whole section.

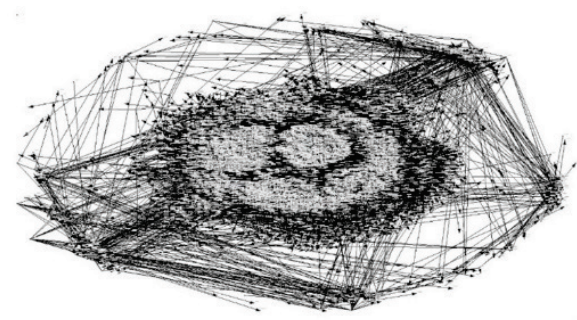

Figure 2 Overall network of MIUI community

Before identifying different user roles, the user's interaction behavior needs to be measured. The out-degree of 19025 users is higher than 0 , indicating that these users have commented on another user at least once, and the average out-degree of all users is 1.3646 ; in-degree shows that 1134 users have received another user's comments, the average number of comments received was 1.3646 too; 23 of all users did not submit an idea or received a comment. The descriptive statistical analysis is shown in Tab.3.

\begin{tabular}{|c|c|c|c|c|c|}
\hline & $N$ & Min & Max & Average & Standard Error \\
\hline Contribution point & 20036 & -4.00 & 1140.00 & 0.92 & 0.12 \\
\hline User credits & 20036 & -168.00 & 406735.00 & 2413.96 & 38.42 \\
\hline In-degree & 20036 & 0.00 & 3835.00 & 1.36 & 0.31 \\
\hline Out-degree & 20036 & 0.00 & 131.00 & 1.36 & 0.12 \\
\hline Effective cases & 20036 & -4.00 & 1140.00 & 0.92 & 0.12 \\
\hline
\end{tabular}

In order to ensure the validity of the clustering results, the SPSS24.0 box diagram is used to identify the outliers. Finally, 17 extreme outliers are deleted from the dataset and analyzed separately to ensure the stability of the clustering effects.

This article clusters the related data between the user's interaction behavior (out-degree and in-degree) and contribution behavior (contribution points and user credits), and filters the community administrators and fake accounts in the MIUI community. In addition, only users with out-degree/in-degree above zero or the contribution point more than zero will be included in the cluster analysis, and 20014 valid sample data will be obtained as the research object of this paper.
In the K-means clustering algorithm, the elbow method is used to determine the divided data groups. As the number of clusters $K$ increases, the sample partitioning will be more refined, and the degree of aggregation of each cluster will gradually increase, so the SSE will gradually become smaller. When $K$ is smaller than the actual number of clusters, the increase of $K$ will greatly increase the degree of aggregation of each cluster, so the decrease of SSE will be large, and when $K$ reaches the suitable number of clusters, the degree of polymerization obtained by increasing $K$ will shrink quickly. And the return will quickly become smaller, so the decline of $S S E$ will be reduced sharply, then tend to be flat as the $K$ value continues to increase, and its corresponding $K$ value is the 
real number of clusters. The relationship between $K$ and SSE is shown in Fig. 3.

As seen from Fig. 3, the $K$ value corresponding to the elbow is 9 , so the optimal cluster number is 9 for the clustering of this data set. We conducted an analysis of variance (ANOVA) to variance to verify its rationality, which is shown in Tab. 4 [29]. The final cluster centers are shown in Tab. 5.

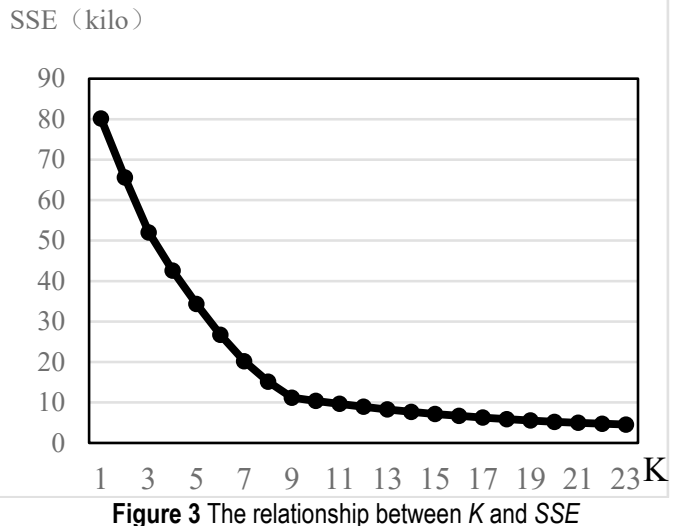

Figure 3 The relationship between $K$ and SSE

\begin{tabular}{|c|c|c|c|c|c|c|}
\hline & \multicolumn{2}{|c|}{ Clustering } & \multicolumn{2}{|c|}{ Errors } & \multirow{2}{*}{$\mathrm{F}$} & \multirow{2}{*}{$\begin{array}{c}\text { Statistical } \\
\text { significance }\end{array}$} \\
\hline & Mean Square & $\mathrm{df}$ & Mean Square & $\mathrm{df}$ & & \\
\hline Zscore (Contribution point) & 2196.381 & 8 & .123 & 20027 & 17852.205 & .000 \\
\hline Zscore(User credits) & 1705.606 & 8 & .319 & 20027 & 5345.442 & .000 \\
\hline Zscore(In-degree) & 2185.987 & 8 & .127 & 20027 & 17187.643 & .000 \\
\hline Zscore(Out-degree) & 1765.341 & 8 & .295 & 20027 & 5979.843 & .000 \\
\hline
\end{tabular}

Table $\mathbf{5}$ The final cluster centers

\begin{tabular}{|l|c|c|c|c|c|c|c|c|c|}
\hline & 1 & 2 & 3 & 4 & 5 & 6 & 7 & 8 & 9 \\
\hline Zscore(Contribution point) & 5.69455 & -.06557 & -.06071 & -.05326 & 10.89939 & $\mathbf{3 2 . 1 2 9 1 4}$ & .09291 & -.01957 & .97207 \\
\hline Zscore(User credits) & $\mathbf{2 0 . 2 8 5 1 9}$ & .15427 & -.20922 & .07663 & 4.40028 & 7.45639 & 1.93757 & .60142 & .92942 \\
\hline Zscore(In-degree) & -.06313 & .63927 & -.03841 & -.04126 & -.04143 & -.06313 & -.02148 & 11.20354 & $\mathbf{3 4 . 0 7 4 2 3}$ \\
\hline Zscore(Out-degree) & 1.81046 & $\mathbf{1 6 . 3 1 7 9 2}$ & -.12954 & 3.06323 & .05941 & -.18475 & .00261 & -.90296 & -.71845 \\
\hline $\mathrm{N}$ & 13 & 31 & 17721 & 586 & 48 & 11 & 1586 & 28 & 12 \\
\hline Percent & .00064 & .00154 & .88446 & .02925 & .00240 & .00055 & .07916 & .00140 & .00060 \\
\hline
\end{tabular}

According to the clustering results, the user roles in the MIUI community can be classified into nine categories. In order to further explore the behavioral differences and participation characteristics of these nine types of user roles, this paper gathers the relevant data of participating users, and analyzes the typical characteristics of each cluster by means of social network metrics and the visual center network of user roles. Fig. 4 depicts the distribution of nine types of user roles from the two dimensions of interaction behavior and contribution behavior (the abscissa is the score obtained by integrating out-degree and in-degree of each type of users, and the ordinate is the score obtained by integrating contribution points and users credit of each type of users.)

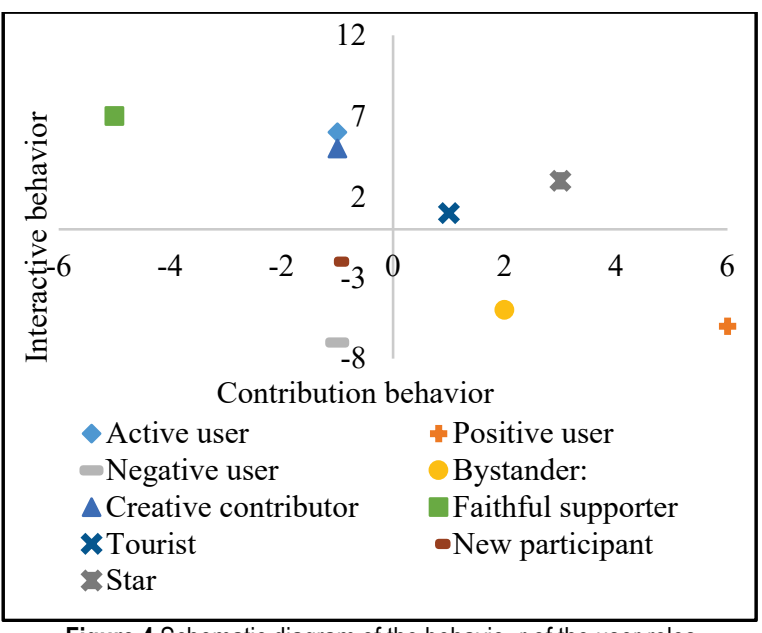

Figure 4 Schematic diagram of the behaviour of the user roles

(1) Active users: This type of users is characterized by overwhelmingly high scores, a low number of creative submissions and a low number of comments. On average, this type of users has out-degree score of 3.92 and indegree of 0 , indicating that this type of users is more actively involved in comments and dialogues with other users, but receives almost no response from other persons; At the same time, the contribution value of such users is at a medium and upper level $(n=67.08)$, but the number of submissions is small, indicating that such users have a longer time in the community, pay more attention to other people's ideas but rarely have their own ideas. Fig. 5 shows the graph of a typical active user's relationship network and capability index.

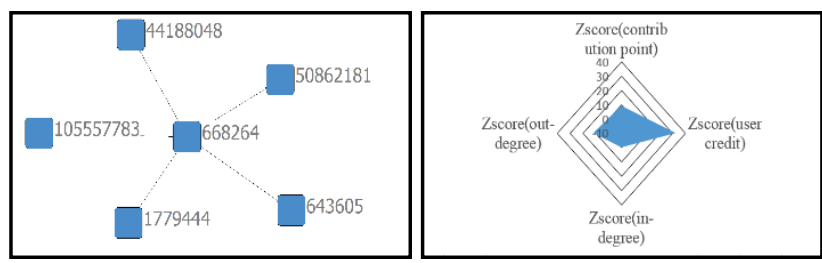

Figure 5 Active user (UID 668264), contribution point 109, user credits 143524, in degree 0 , out degree 18

(2) Positive users: This type of users has a high level of comment behaviors, with an average of 6.74 input relationships and 25.52 output relationships. Compared with other user roles, this type of users has the most prominent comment behaviors, but its contribution points are almost zero, and the level of user credits is also very low, indicating that such users have shorter activities in the community and will make a lot of comments in a certain period of time. Fig. 6 shows the diagram of a typical positive user's relationship network and capability index. 

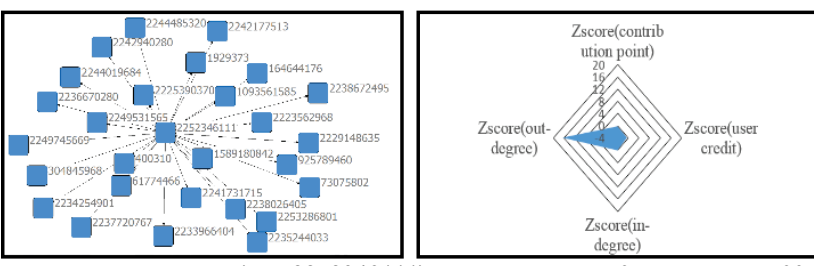

Figure 6. Positive user (UID 2252346111), contribution point 0 , user credits 509 indegree 2, outdegree 25

(3) Negative users: This type of users has the highest proportion, which is similar to the results of previous scholars [30]. The final aggregation center indicator values for all four variables are the lowest of all clusters. Therefore they are defined as the negative users in the community. Their scores are very low in the community, for publishing no ideas on the platform or actively participating in comments and voting on others' comments. Overall, the level of user's activity is very low.

(4) Bystanders: This type of users is characterized by high out-degree and user credits, with an average of 5.70 and 2709.97, respectively. However, the value of submitting comments is not very high, and has not been known by the public. Therefore, the contribution and indegree of these users are relatively low. Fig. 7 is a diagram of the relationship network and capability index of a typical bystander user.
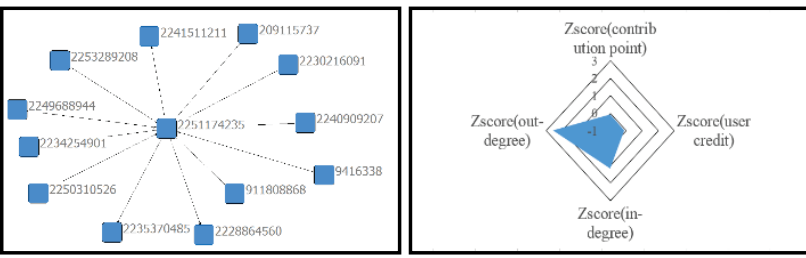

Figure 7 Bystander (UID 2251174235), contribution point 0, user credits 1792, indegree 12 , outdegree 5

(5) Creative contributors: The contribution values and user credits of such users are at a high level, and they also have a certain attention to other users' ideas, but they receive very few comments. According to the analysis of the topic content published by creative contributors, the suggestions are too professional to let the common users resonate. Fig. 8 is a diagram of the relationship network and capability index of a typical creative user.
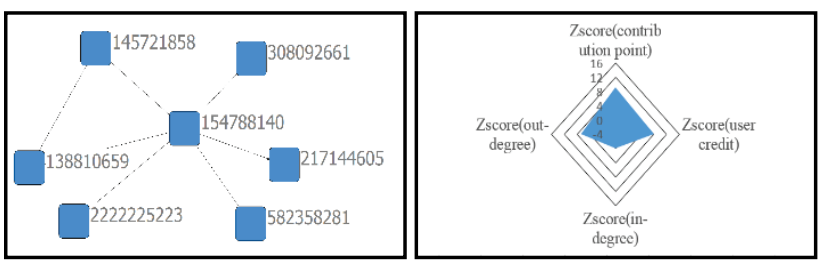

Figure 8 Creative contributor (UID 154788140), contribution point 109, user credits 37426 , indegree 0 , outdegree 11

(6) Faithful supporters: The contributions of such users reached the highest level, averaging 374.90; the level of points ranked second among the 9 categories of users. From the perspective of out-degree\&in-degree analysis, these users rarely publish their opinions in the community. It can be concluded that this user group is a loyal fan of the Xiaomi brand and belongs to loyal users.

(7) Tourists: The user credits are relatively high, but the other three indicators are at the middle level of the entire user group, indicating that these users have a long online time, and occasionally put forward their own ideas or comments on other users' ideas. In general, this type of user is not engaged enough.

(8) New participants: This type of users has a high level of n-degree, but the level of user credits and outdegree is very low. Comparing with the registration time and posting content, most of the users' registrations are late, and the content of the post is for help, so it obtained large comments in a short time.

(9) Stars: The users' in-degree reached the highest level of 34.07, and the contribution points and user credits levels are the fourth and fifth, respectively, but the outdegree level is the eighth. This type of users has received widespread attention in the community, but its contribution is not high. Researching their contents found that the posts receiving a lot of attention are about how to improve the users' experience. This user group stands at the forefront of user needs and has a strong motivation to seek solutions. Fig. 9 is a diagram showing the relationship network and capability index of a typical Star.

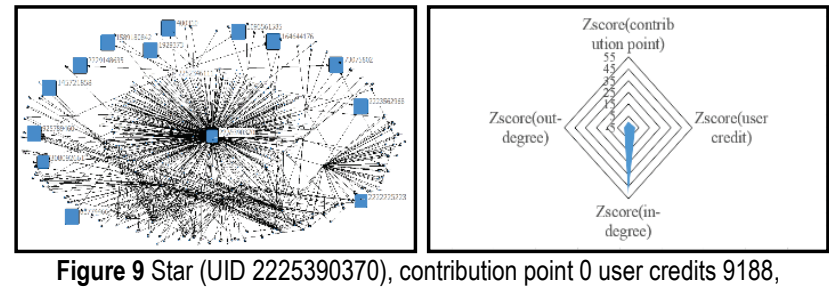
indegree 497, outdegree 11

\section{DISCUSSION}

The classification result shows that heterogeneity between users truly exists. According to users' interaction behavior and contribution behavior, the case this paper investigated owns 9 different types of user roles. The result also can inspire community managers to adjust their strategies, strengthen bonds between users and encourage participation and design encouragement targeted for each user role. For enterprises, managerial implications can be generalized as the following.

(1) Focus on core users. Research shows that the network structure of the "developer communication" section of Xiaomi MIUI community is a typical "coreedge" structure, so it is necessary to focus on core users (active users, positive users, , creative users, and Stars) for their leading role, especially the stars who have a great influence in the community because they have a profound impact on product innovation and other members of the community. It is necessary to strengthen the training scale of core users, encourage core users to actively establish contacts with marginal users, improve the connection strength and network density among members, and contribute to the creation of innovative ideas in the community and improve the quality of innovation.

(2) Continue to pay attention to marginal users. Users participate in the community just for curiosity or interest at the beginning. They have not yet developed a sense of dependence and belonging. The company has not yet formed an effective user guidance system, so every community has a large number of marginal users (negative users, bystanders, tourists, new participants). In order to 
keep more people in the community, core personnel need to take the responsibility of answering user questions and improving these users' satisfaction with the community. In this way, core members and other community members will establish a wide range of interactions.

(3) Multi-dimensional perfect user guidance mechanism. Different from the intermediary crowdsourcing platform, the purpose of self-built crowdsourcing innovative virtual community is not only to pay more attention to the users' actual needs' feedback information but also to improve the users ' recognition of the product. Therefore, enterprises need to improve the users' guiding mechanism from multiple dimensions. For example, for creative contributors, considering their passion for creative input and creative design, the administrator can combine the concept of gamification and set up "The Design Masters Modal" and "The Creative Talents Modal". The modals can encourage creative contributors to participate continuously. For faithful supporters, it can develop a product internal testing service to enable supporters to have priority to experience the product's features before the product is officially launched, ensuring further enhancement of their loyalty.

\section{CONCLUSIONS AND SUGGESTIONS}

It is important to analyze the user participation role of crowdsourcing innovative virtual community and explore the participation behavior of different user roles. It is of great significance to guide and motivate the public to actively and continuously participate in crowdsourcing innovation and enhance the performance of crowdsourcing innovation. Based on social network analysis and cluster analysis methods, this paper proposes the user role recognition process of crowdsourcing innovative virtual community, conducting empirical research with "developer communication" section. A key contribution of this study is the identification of nine distinct user roles within the community. And all of those user roles display significant difference in terms of interaction behavior and contribution behavior. The behavioral characteristics provide a theoretical basis for understanding the heterogeneity of users in the crowdsourcing innovation community, and also provide reference for enterprises to carry out effective crowdsourcing innovation virtual community governance and enhance the innovation performance.

Although the model has good universality for including innovative contribution behavior unique to crowdsourced innovation community users and interactive behavior available to all online community. The research also has the following limitations: the relevant data is only from "developer communication" section, mainly considering that the section has strong crowdsourcing innovation features and does not show the entire audience of the entire Xiaomi MIUI community. In addition, this paper just analyzes the objective data of users in community participation, ignoring the characteristics of users' participation motivation and their own knowledge and ability. The solution of these problems can be used as a direction for further exploration. Future studies need to take qualitative content analysis regarding user's comments and ideas into consideration. Overall, a major field is the one exploring different user types with the motives and personalities and how these motives might influence the crowdsourcing innovation performance.

\section{Acknowledgments}

This research was supported by Social Science Fund of MOE under Grant 19YJA630055, Jiangsu Social Science Fund under Grant 18HQ003 and Jiangsu Social Science Fund under Grant 019SJA1908.

\section{REFERENCES}

[1] Howe, J. (2006). The rise of crowdsourcing. Wired magazine, 14(6), 1-4.

[2] Bayus, B. L. (2013). Crowdsourcing new product ideas over time: An analysis of the Dell IdeaStorm community. Management Science, 59(1), 226-244. https://doi.org/10.1287/mnsc.1120.1599

[3] Jeppesen, L. B. \& Frederiksen, L. (2006). Why do users contribute to firm-hosted user communities? The case of computer-controlled music instruments. Organization Science, 17(1), 45-63. https://doi.org/10.1287/orsc.1050.0156

[4] Brabham, D. C. (2008). Moving the crowd at iStockphoto: The composition of the crowd and motivations for participation in a crowdsourcing application. First Monday, 13(6), 236-238. https://doi.org/10.5210/fm.v13i6.2159

[5] Geiger, D. \& Schader, M. (2014). Personalized task recommendation in crowdsourcing information systems Current state of the art. Decision Support Systems, 65(C), 316. https://doi.org/10.1016/j.dss.2014.05.007

[6] Mo, Z., Luo, C., \& Liu, X. L. (2014). Research on Conceptual Model of Crowdsourcing Based on IS Perspective. Science and Technology Management Research, 34(14), 155-161. (in Chinese)

[7] Wexler, M. N. (2011). Reconfiguring the sociology of the crowd: exploring crowdsourcing. International Journal of Sociology \& Social Policy, 31(1/2), 6-20. https://doi.org/10.1108/01443331111104779

[8] Boudreau, K. J. \& Lakhani, K. R. (2013). Using the crowd as an innovation partner. Harvard Business Review, 91(4), 60-9, 140.

[9] Sun, Y., Fang, Y., \& Lim, K. H. (2012). Understanding sustained participation in transactional virtual communities. Decision Support Systems, 53(1), 12-22. https://doi.org/10.1016/j.dss.2011.10.006

[10] Martinez, M. G. (2017). Inspiring crowdsourcing communities to create novel solutions: Competition design and the mediating role of trust. Technological Forecasting and Social Change, 117, 296-304. https://doi.org/10.1016/j.techfore.2016.11.015

[11] Füller, J., Hutter, K., \& Hautz, J. (2014). User roles and contributions in innovation-contest communities. Journal of Management Information Systems, 31(1), 273-308. https://doi.org/10.2753/MIS0742-1222310111

[12] Zhang, D. (2017). High-speed Train Control System Big Data Analysis Based on Fuzzy RDF Model and Uncertain Reasoning. International Journal of Computers, Communications \& Control, 12(4). https://doi.org/10.15837/ijccc.2017.4.2914

[13] Zhang, X. \& Wang, C., (2012). Network positions and contributions to online public goods: The case of Chinese Wikipedia. Journal of Management Information Systems, 29 (2), 11-40. https://doi.org/10.2753/MIS0742-1222290202

[14] Guo, W., Zheng, Q., An, W., \& Peng, W. (2017). User roles and contributions during the new product development process in collaborative innovation communities. Applied Ergonomics, 63,106-114. https://doi.org/10.1016/j.apergo.2017.04.013 
[15] Fuger, S., Schimpf, R., Füller, J., \& Hutter, K. (2017). User roles and team structures in a crowdsourcing community for international development-a social network perspective. Information Technology for Development, 23(1), 1-25. https://doi.org/10.1080/02681102.2017.1353947

[16] Brem, A. \& Bilgram, V. (2015). The search for innovative partners in co-creation: Identifying lead users in social media through netnography and crowdsourcing. Journal of Engineering and Technology Management, 37, 40-51. https://doi.org/10.1016/j.jengtecman.2015.08.004

[17] Shen, X. L., Lee, M. K. O., \& Cheung, C. M. K. (2014). Exploring online social behavior in crowdsourcing communities: A relationship management perspective. Computers in Human Behavior, 40, 144-151. https://doi.org/10.1016/j.chb.2014.08.006

[18] Cetină, I., Dumitrescu, L., Fuciu, M., Orzan, G., \& Stoicescu, C. (2018). Modelling the influences of online social networks on consumers' buying behaviour. Economic Computation \& Economic Cybernetics Studies \& Research, 52(2). https://doi.org/10.24818/18423264/52.2.18.01

[19] Martinez, T. R. \& Olmedilla, M. (2016). Identification of innovation solvers in open innovation communities using swarm intelligence. Technological Forecasting \& Social Change, 109, 15-24. https://doi.org/10.1016/j.techfore.2016.05.007

[20] Zhang, S. S., Liang, X., \& Qi, J. S. (2017). A Review of Social Network Role Recognition Methods. Chinese Journal of Computers, 40(03), 649-673. (in Chinese)

[21] Lee, J. \& Seo, D. B. (2016). Crowdsourcing not all sourced by the crowd: An observation on the behavior of Wikipedia participants. Technovation, S0166497216300311. https://doi.org/10.1016/j.technovation.2016.05.002

[22] Liu, M. T., Li, H. G., \& Zhu, X. G. (2016). An Empirical Study of User Knowledge Sharing Level and Participation Behavior in Virtual Community. Science and Technology Management Research, 36(16), 155-159. (in Chinese)

[23] Qi, G. J. \& Li, Y. Y. (2016). Research on the contribution degree of Online Users in the Open Innovation Communities for Enterprises. Science \& Technology Progress and Policy, 33(14), 81-87.

[24] Toral, S. L., Martínez-Torres, M. R., \& Barrero, F. (2010). Analysis of virtual communities supporting OSS projects using social network analysis. Information and Software Technology, 52(3), 296-303. https://doi.org/10.1016/j.infsof.2009.10.007

[25] Billenstein, D., Dinkel, C., \& Rieg, F. (2018). Automated topological clustering of design proposals in structural optimisation. International Journal of Simulation Modelling, 17(4), 657-666. https://doi.org/10.2507/IJSIMM17(4)454

[26] Pamucar, D. \& Ćirović, G. (2018). Vehicle route selection with an adaptive neuro fuzzy inference system in uncertainty conditions. Decision Making: Applications in Management and Engineering, 1(1), 13-37. https://doi.org/10.31181/dmame180113p

[27] Sremac, S., Tanackov, I., Kopić, M., \& Radović, D. (2018). ANFIS model for determining the economic order quantity. Decision Making: Applications in Management and Engineering, 1(2), 81-92. https://doi.org/10.31181/dmame1802079s

[28] Parthiban, K. \& Sujatha, S. (2018). Similarity-based clustering and security assurance model for big data processing in cloud environment. Economic Computation \& Economic Cybernetics Studies \& Research, 52(2). https://doi.org/10.24818/18423264/52.2.18.11

[29] Tang, M., Gong, D., Liu, S., \& Lu, X. (2017). Finding key factors affecting the locations of electric vehicle charging stations: a simulation and ANOVA approach. International Journal of Simulation Modelling, 16(3). https://doi.org/10.2507/IJSIMM16(3)C015
[30] Koch, G., Hutter, K., Decarli, P., \& Füller, J. (2013). Identifying participants' roles in open government platforms and its impact on community growth. In: Hawaii International Conference on System Sciences, IEEE, 19001910. https://doi.org/10.1109/HICSS.2013.254

\section{Contact information:}

Qingliang MENG, Professor (Corresponding author) School of Management \& Economics, Jiangsu University of Science and Technology, 301, Xuefu Road, Zhenjiang, Jiangsu 212013, China E-mail: mengzhi007@163.com

Yi HANG, Postgraduate

School of Management \& Economics, Jiangsu University of Science and Technology, 301, Xuefu Road, Zhenjiang, Jiangsu 212013, China E-mail: castleyhang@163.com

Xiaojun CHEN, Instructor

School of Management \& Economics, Jiangsu University of Science and Technology, 301, Xuefu Road, Zhenjiang, Jiangsu 212013, China E-mail: chenxj2006@163.com 